\title{
Study on calculation of stress intensity factor using finite element method
}

\author{
aLin Li, ${ }^{\mathrm{b}}$ Dan YANG \\ ${ }^{a}$ Fujian Jiangxia University, Fuzhou, Fujian, P. R. China \\ ${ }^{b}$ Huazhong University of Science and Technology, Wuhan, Hubei, P.R. China
}

KEYWORD: Stress intensity factor; the finite element method; ordinary element; singular element ABSTRACT: Stress intensity factor can reflects the stability of cracks. it is important to study accurate calculation method of stress intensity factor. in this study, the finite element method with modeling using ordinary element and singular element is applied to calculate stress intensity factor. it is shown that calculation result from the finite element model using singular element is more accurate than that from the finite element model using ordinary element.

\section{INTRODUCTION}

Cracks in concrete result in stress concentration, which may cause failure of structures with cracks under low stress level. A lot of studies were carried out on fracture criterion of cracks. Erdogan proposed maximum stress hypothesis, which can predict fracture angle accurately. However, the hypothesis is not suitable to predict fracture toughness(Erdogan \& Sih 1963). Stain-energy-density factor proposed by Sih is widely applied to mixed mode crack problems(Sih 1974). Based on the principle of energy conservation, an energy-based approach for the finite element modeling of mixed mode cohesive crack propagation was developed. Compared to the strength-based cohesive crack modeling approach, the energy-based approach is both theoretically more fundamental and numerically more effecient(Xie \& Gerstle 1995). An analytical model was developed to determine the effects of progressive reduction in stiffness as crack formation due to thermal stresses, which was verified by experimental data(Elbadry \& Ghali 1995). The cracking of reinforced concrete beams, with and without prestressing, resulted from the temperature gradient was studied. it is shown that the partially prestressed cracked member provided with nonprestressed steel has the advantage of limiting the width of cracks(Ariyawardena et al. 1997). Stability of cracks is crucial to structural safety. Since stress intensity factor can reflect the stability of cracks, it is important to study accurate calculation method of stress intensity factor.

\section{STRESS INTENSITY FACTOR}

\section{Fracture mode}

There are three basic fracture modes, as shown in Figure 1. Mode I, mode II and mode III are tensile fracture, in-plane shear fracture and anti-plane shear fracture, respectively. Tensile stress is perpendicular to the fracture surface in mode I. Shear stress is parallel to the fracture surface, and perpendicular to the fracture front in mode ii. Shear stress is parallel to the fracture surface and the fracture front in mode III. Not all fracture problems can be simplified as one of three basic modes in actual engineering. There are mixed modes, which are combination of three basic modes.

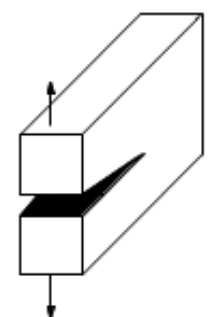

(a) mode I

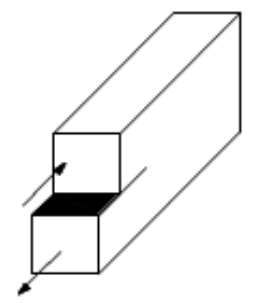

(b) mode II

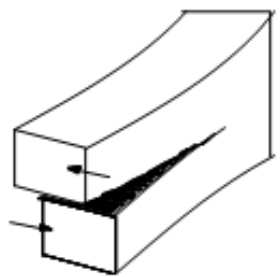

(c) mode III

Figure 1. Fracture modes 


\section{Analysis of stress intensity factor}

Since fracture strength is affected significantly by the deformation in the field near crack tip, it is necessary to analyze the displacements and stresses in the field.

Since crack size is much smaller than structure size, crack can be supposed to located on an infinite plate. The crack length is $2 \mathrm{a}$ and tensile stresses are exerted on the plate in the directions of $x$ and $y$ axes in mode I, as shown in Figure 2. For convenience, the crack tip is taken as the origin of coordinates.

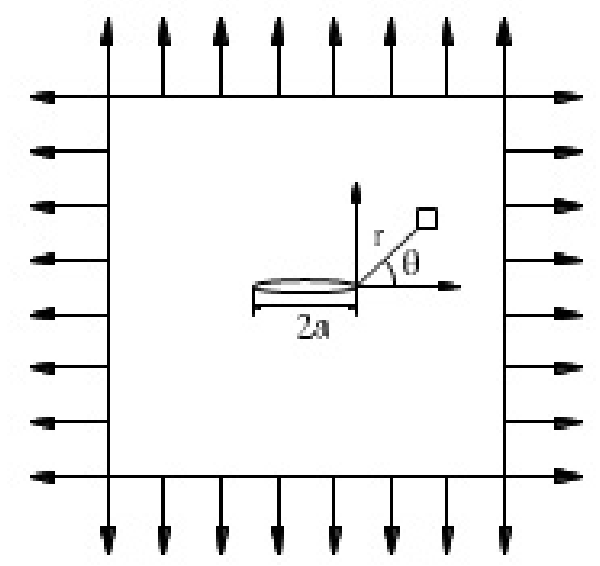

Figure 2. diagram of crack

According to the solution to the elastic plane problem, the stress and displacement at a point near the crack tip, $P(r, \theta)$, are as follows

$$
\begin{aligned}
& \sigma_{x}=\frac{K_{\mathrm{I}}}{\sqrt{2 \pi r}} \cos \frac{\theta}{2}\left(1-\sin \frac{\theta}{2} \sin \frac{3 \theta}{2}\right) \\
& \sigma_{y}=\frac{K_{\mathrm{I}}}{\sqrt{2 \pi r}} \cos \frac{\theta}{2}\left(1+\sin \frac{\theta}{2} \sin \frac{3 \theta}{2}\right) \\
& \tau_{x y}=\frac{K_{\mathrm{I}}}{\sqrt{2 \pi r}} \sin \frac{\theta}{2} \cos \frac{\theta}{2} \cos \frac{3 \theta}{2} \\
& \tau_{x z}=\tau_{y z}=0 \\
& \sigma_{z}=\mathrm{v}\left(\sigma_{x}+\sigma_{y}\right) \quad \text { (plane strain) } \\
& \sigma_{z}=0 \quad \text { (plane stress) } \\
& \left.u=\frac{2(1+v) K_{\mathrm{I}}}{4 E} \sqrt{\frac{r}{2 \pi}}\left[(2 k-1) \cos \frac{\theta}{2}-\cos \frac{3 \theta}{2}\right]\right) \\
& v=\frac{2(1+v) K_{\mathrm{I}}}{4 E} \sqrt{\frac{r}{2 \pi}}\left[(2 k+1) \sin \frac{\theta}{2}-\sin \frac{3 \theta}{2}\right] \\
& w=0 \\
& \text { (plane strain) } \\
& w=-\int \frac{V}{E}\left(\sigma_{x}+\sigma_{y}\right) d z \quad \text { (plane stress) }
\end{aligned}
$$

Where $r$ and $\theta$ are polar coordinates of a point near crack tip. $u, v$ and $w$ are displacement components along $x, y$ and $z$ axes. $\sigma_{x}, \sigma_{y}, \tau_{x y}, \sigma_{z}, \tau_{x z}$ and $\tau_{y z}$ are stress components. $E$ and $v$ are respectively elastic modulus and Poisson's ratio. $k$ and $K_{\mathrm{I}}$ are modulus of dilatation and stress intensity factor, respectively.

$$
k= \begin{cases}3-4 v, & \text { (plane strain) } \\ \frac{3-v}{1+v}, & \text { (plane stress) }\end{cases}
$$




$$
K_{\mathrm{I}}=\sigma \sqrt{\pi a}
$$

Similarly, the stress, displacement and stress intensity factor of mode II are as follows

$$
\begin{aligned}
& \left.\sigma_{x}=\frac{-K_{\mathrm{II}}}{\sqrt{2 \pi r}} \sin \frac{\theta}{2}\left(2+\cos \frac{3 \theta}{2} \cos \frac{3 \theta}{2}\right)\right) \\
& \sigma_{y}=\frac{K_{\mathrm{II}}}{\sqrt{2 \pi r}} \sin \frac{\theta}{2} \cos \frac{\theta}{2} \cos \frac{3 \theta}{2} \\
& \tau_{x y}=\frac{K_{\mathrm{II}}}{\sqrt{2 \pi r}} \cos \frac{\theta}{2}\left(1-\sin \frac{\theta}{2} \sin \frac{3 \theta}{2}\right) \\
& \tau_{x z}=\tau_{y z}=0 \\
& \sigma_{z}=v\left(\sigma_{x}+\sigma_{y}\right) \quad \text { (plane strain) } \\
& \sigma_{z}=0 \quad \text { (plane stress) } \\
& u=\frac{2(1+v) K_{\mathrm{II}}}{4 E} \sqrt{\frac{r}{2 \pi}}\left[(2 k+3) \sin \frac{\theta}{2}+\sin \frac{3 \theta}{2}\right] \\
& \left.v=\frac{2(1+v) K_{\mathrm{II}}}{4 E} \sqrt{\frac{r}{2 \pi}}\left[(2 k-2) \cos \frac{\theta}{2}+\cos \frac{3 \theta}{2}\right]\right\} \\
& w=0 \quad \text { (plane strain) } \\
& w=-\int \frac{V}{E}\left(\sigma_{x}+\sigma_{y}\right) d z \quad \text { (plane stress) } \\
& K_{\mathrm{II}}=\tau \sqrt{\pi a}
\end{aligned}
$$

Corresponding components of mode III has following expressions

$$
\left.\begin{array}{c}
\sigma_{x}=\sigma_{y}=\sigma_{z}=\tau_{x y}=0 \\
\tau_{x z}=\frac{K_{\mathrm{III}}}{\sqrt{2 \pi r}} \sin \frac{\theta}{2} \\
\tau_{y z}=\frac{K_{\mathrm{III}}}{\sqrt{2 \pi r}} \cos \frac{\theta}{2}
\end{array}\right\}
$$

From above stress expressions of mode I, II and III, it can be found that stresses can not be acted as strength condition. However, stress intensity factor is finite, which represents strength of stress field.It is appropriate for stress intensity factor to establish fracture criterion.

\section{CALCUALTION OF STRESS INTENSITY FACTOR USING FININTE ELEMENT ME- THOD}

Calculation method of stress intensity factor

Calculation method of stress intensity factor can be classified into three categories: analytical method, the finite element method and experimental method. Analytical method is an exact one, which is suitable for solving problems with simple geometrical shapes. Stress intensity factors can be consulted from references for simple structures. However, it is difficult for complex structures to calculate stress intensity factors using analytical method. It is common for most structures to calculate stress intensity factors using the finite element method. in some special cases, stress intensity factors 
need to be verified by experiment. Following study focuses on the finite element method for calculating stress intensity factors.

There are two types of elements to simulate crack, ordinary elements and singular elements. When ordinary elements are selected, stress intensity factor is derived from stresses and displacements in the field near crack tip. When singular elements are selected, stress intensity factor is calculated directly.

\section{Ordinary element}

The displacement, $v_{i}$, and coordinate, $r_{i}$, at an integration point of ordinary element near crack tip can be obtained from finite element program. Substituting $\theta=\pi$ into Equation (2) yields

$$
v_{i}=\frac{(k+1)(1+v)}{E} K_{\mathrm{Ii}} \sqrt{\frac{r_{i}}{2 \pi}}
$$

Substituting Equation (3) into Equation (11) yields

$$
K_{\mathrm{I} i}= \begin{cases}\frac{E}{4} v_{i} \sqrt{\frac{2 \pi}{r_{i}}} & \text { (plane stress) } \\ \frac{E}{4(1-v)^{2}} v_{i} \sqrt{\frac{2 \pi}{r_{i}}} & \text { (plane strain) }\end{cases}
$$

Suppose $K_{\mathrm{I}}$ is a linear function of $r$. Based on the least square method and data derived from Equation (12), following equation can be obtained

$$
K_{\mathrm{I}}=A r+B
$$

When $r=0, K_{\mathrm{I}}=B$.

Similarly, stress intensity factor can also be derived from the extrapolation method based on stress, where data for curve fitting are obtained from Equation (1). For mode II and mode III fractures, stress intensity factors can be derived from Equation (6) and Equation (9), respectively.

it should be noted that the stress intensity factors derived from the extrapolation method vary according to mesh density.

\section{Singular element}

Singularity can be reflected by singular element, which has little related to mesh density. Singular elements include triangular element with singular strain, isoparametric element with singular strain. A singular element in ANSYS program is shown in Figure 3.

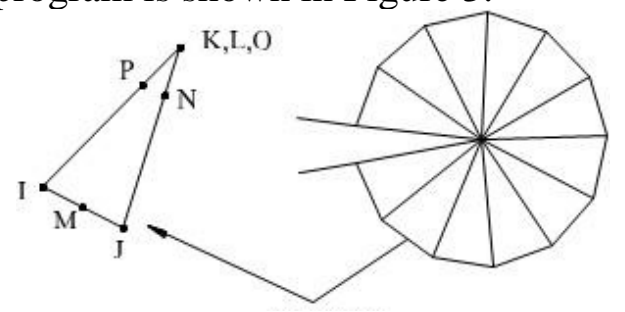

Figure 3. diagram of PLANE82

\section{NUMERICAL EXAMPLE}

A plate with mode I fracture was simulated using ANSYS program. The length, width and thickness of the plate is $200 \mathrm{~mm}, 400 \mathrm{~mm}$ and $1 \mathrm{~mm}$, respectively. The length of crack is $40 \mathrm{~mm}$. Modulus of elasticity and Poisson's ratio is $2 \times 10^{5} \mathrm{MPa}$ and 0.25 , respectively. $\sigma$ is $30 \mathrm{MPa}$, as shown in Figure 4. 


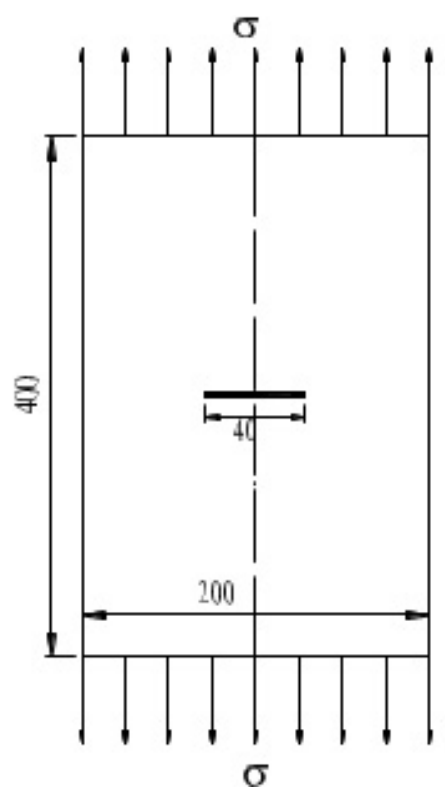

Figure 4. diagram of a plate with mode I fracture

The analytical expression of stress intensity factor has the following form

$$
K_{\mathrm{I}}=\sigma \sqrt{\pi a} \sqrt{\sec \frac{\pi a}{2 W}}\left[1-0.025\left(\frac{a}{w}\right)^{2}+0.06\left(\frac{a}{w}\right)^{4}\right]
$$

Based on the Equation (14), the analytical solution of stress intensity factor is obtained, $K_{\mathrm{I}}=243.6 \mathrm{Mpa} \cdot \sqrt{\mathrm{mm}}$.

The crack was first simulated using ordinary element, and the mesh near the crack was refined. A half of the plate was analyzed according to symmetry. Total element number is 9640 , as shown in Figure 5. The deformation of the field around the crack is shown in Figure 6.

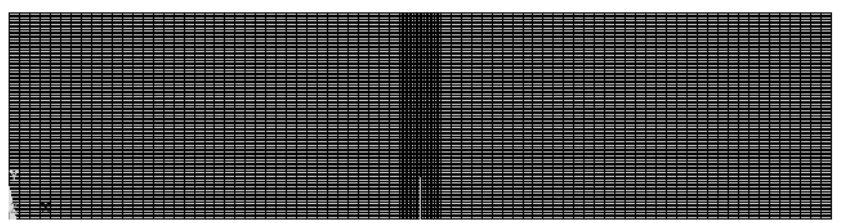

Figure 5. diagram of model meshed with ordinary element

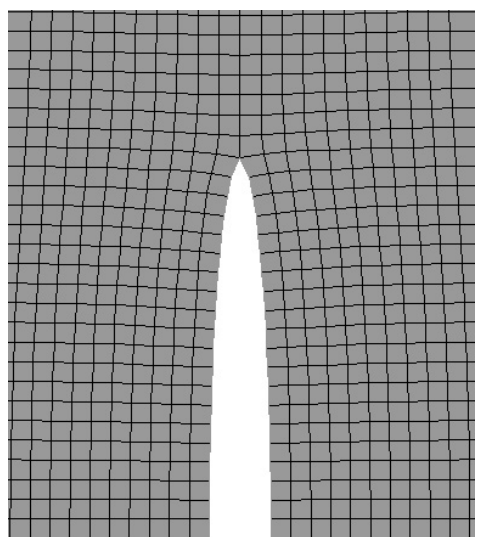

Figure 6. deformation of the field around the crack

Based on the displacements near the crack tip, stress intensity factor was obtained, $K_{\mathrm{I}}=243.9 \mathrm{Mpa} \cdot \sqrt{\mathrm{mm}}$. 
in order to analyze the effect of element size, the sizes of all elements were doubled. There are 2410 elements in this case, and $K_{\mathrm{I}}=238.2 \mathrm{Mpa} \cdot \sqrt{\mathrm{mm}}$.

Finally, the crack was modeled using singular element, as shown in Figure 7. Stress intensity factor was calculated, $K_{\mathrm{I}}=243.7 \mathrm{Mpa} \cdot \sqrt{\mathrm{mm}}$. All solutions are listed in

Conclusion

Stress intensity factor can be obtained by finite element analysis with modeling using ordinary element or singular element. Error in the model using ordinary element is larger than that in the model using singular element. Moreover, calculation results from the finite element model using ordinary element vary from element size to element size. Therefore, it is more appropriate to calculate stress intensity factor by singular element.

Table 1.

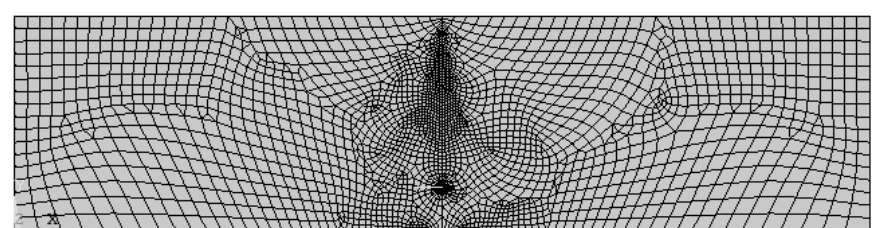

Figure 7. diagram of model meshed with singular element

\section{CONCLUSION}

Stress intensity factor can be obtained by finite element analysis with modeling using ordinary element or singular element. Error in the model using ordinary element is larger than that in the model using singular element. Moreover, calculation results from the finite element model using ordinary element vary from element size to element size. Therefore, it is more appropriate to calculate stress intensity factor by singular element.

Table 1. Solutions to stress intensity factor

\begin{tabular}{|c|c|c|c|c|}
\hline & $\begin{array}{l}\text { Ana- } \\
\text { lytical } \\
\text { solu- } \\
\text { tion }\end{array}$ & $\begin{array}{l}\text { Ordi- } \\
\text { nary } \\
\text { ele- } \\
\text { ment }\end{array}$ & $\begin{array}{c}\text { Ordi- } \\
\text { nary } \\
\text { ele- } \\
\text { ment } \\
\text { with } \\
\text { large } \\
\text { size }\end{array}$ & $\begin{array}{c}\text { Singu- } \\
\text { lar ele- } \\
\text { ele- } \\
\text { ment }\end{array}$ \\
\hline $\begin{array}{l}\mathrm{K}_{\mathrm{i}} \\
\mathrm{Mpa} \cdot \sqrt{\mathrm{mm}}\end{array}$ & 243.6 & 243.9 & 238.2 & 243.7 \\
\hline $\begin{array}{l}\text { Error } \\
\%\end{array}$ & 0 & 0.13 & 2.21 & 0.03 \\
\hline
\end{tabular}

\section{ACKNOWLEDGEMENTS}

The authors acknowledge the financial support by the National Natural Science Foundation of China (Grant No. 51278214).

\section{REFERENCES}

[1] Ariyawardena, N., Ghali, A. \& Elbadry, M. 1997. Experimental study on thermal cracking in reinforced concrete members. ACi Structural Journal 94(4): 432-441.

[2] Elbadry, M. \& Ghali, A. 1995. Control of thermal cracking of concrete structures. ACi Structural Journal 92(4): 435-450.

[3] Erdogan, F. \& Sih, G. C. 1963. On the crack extension in plates under plane loading and transverse shear. Journal of Basic Engineering 85(4): 519-525.

[4] Sih, G. C. 1974. Strain-energy-density factor applied to mixed mode crack problems. interna- 
tional Journal of Fracture 10(3): 305-321.

[5] Xie, M. \& Gerstle, W. 1995. Energy-Based cohesive crack propagation modeling. Journal of Engineering Mechanics 121(12): 1349-1358. 